\title{
Interactive comment on "Seasonal variability in methane and nitrous oxide fluxes from tropical peatlands in the Western Amazon basin" by Yit Arn Teh et al.
}

Yit Arn Teh et al.

yateh@abdn.ac.uk

Received and published: 20 March 2017

1. Although the number of studies on trace gas fluxes from lowland tropical peatlands are steadily increasing, measurements are completely absent from some important large peatland areas. The peats in the foreland basin of Pastaza Maranon (PMFB) in Peru is an example of an important tropical peatland area from which we have no empirical studies on $\mathrm{CH} 4$ and $\mathrm{N} 2 \mathrm{O}$ fluxes. As such, this study is timely and novel. The authors conducted chamber based $\mathrm{CH} 4$ and $\mathrm{N} 2 \mathrm{O}$ fluxes stratified according to the four dominant vegetation types ranging from nutrient rich floodplains to nutrient poor bogs. While the spatial resolution of the sampling is good (see Table 1) the temporal resolution is restricted to four time sampling over a period of two years (sampling twice 
during the wet season and twice during a dry season). However, given the difficult accessibility and the fact that this is the first report on fluxes from this important peat area this is acceptable for this initial study. Furthermore, we do learn important controls since supporting variables were measured as well. Nevertheless if have several point that should be addressed before the manuscript can be accepted for publication.

Authors' response: The authors would like to thank the referee for his/her thoughtful and insightful comments on our manuscript, and welcome the opportunity to improve the manuscript for the wider readership of Biogeosciences.

2. In your introduction, I miss a section on the known controls of $\mathrm{CH} 4$ and $\mathrm{N} 2 \mathrm{O}$ fluxes in peatlands. I think it is important to include this, since it is otherwise unclear why you measured the environmental variables that you did. Are there some potentially important factors that you did not measure and if so, why was that the case?

Authors' response: This was an oversight on our part. In order to keep the paper succinct, we omitted a more detailed review of the literature on the factors regulating $\mathrm{CH} 4$ and $\mathrm{N} 2 \mathrm{O}$ fluxes. We will provide a more through description of the process-based on controls on $\mathrm{CH} 4$ and $\mathrm{N} 2 \mathrm{O}$ flux in the revised version of the manuscript.

With respect to potentially important factors that we did not measure; we did not quantify $\mathrm{CH} 4$ fluxes from woody plants nor did we specifically seek to quantify ebullition. While plant-mediated fluxes are believed to be important in tropical wetland ecosystems (Pangala et al., 2013), we did not have enough data on floristic composition or individual plant identities within our plots to come-up with a sampling design that would adequately represent plant-mediated fluxes from our study sites. Likewise, ebullition is often characterized by high spatial and temporal variability. In order to develop a representative, spatially-stratified sampling design to quantify ebullition, using techniques such as the inverted "flux funnel" approach (Strack et al., 2005), more detailed information on spatial patterns in net $\mathrm{CH} 4$ flux would be required; information that we did not have prior to the collection of the data presented here. As a consequence, we chose

Printer-friendly version

Discussion paper 
to omit specific measurements of ebullition from this study, with a wider view towards collecting these data at a later date.

For $\mathrm{N} 2 \mathrm{O}$, even though inorganic $\mathrm{N}$ is thought to be one of the major drivers of $\mathrm{N} 2 \mathrm{O}$ flux, we did not collect data on inorganic $\mathrm{N}(\mathrm{NH} 4+, \mathrm{NO} 3-)$, because the relatively modest budget for this project did not accommodate costs for inorganic $\mathrm{N}$ analysis.

3. In I.142 and I.147 you mention soil Ca, it remains a mystery in which form this $\mathrm{Ca}$ occurs. Please provide more details, is $\mathrm{Ca}$ an important environmental control on $\mathrm{CH} 4$ or N2O fluxes?

Authors' response: The $\mathrm{Ca}$ in these systems occurs as dissolved inorganic $\mathrm{Ca2}+$ associated with the soil or peat exchange complex, or Ca found in secondary minerals (Lahteenoja et al., 2009). As far as we are aware, Ca has no direct effect on $\mathrm{CH} 4$ or $\mathrm{N} 2 \mathrm{O}$ fluxes, although $\mathrm{Ca}$ may indirectly influence trace gas exchange by influencing plant productivity and organic matter decay. We will revise the text to acknowledge this and remove any ambiguity from the manuscript.

4. You describe your chambers as floating static chambers (I. 179). You furthermore write that chamber were placed on the soil surface from a distance of no closer than $2 m$ to reduce the risk of ebullition (I. 186). For me it is hard to believe that ebullition was completely excluded and I also cannot understand how you can place these chambers at a distance of $2 \mathrm{~m}$ ? Nobody has arms that long (at least I don't), so how was this done in detail? And, especially, how did you take the gas samples from your chambers using syringes without causing ebullition?

Authors' response: The referee is correct that we were unable to entirely exclude ebullition from our dataset. We did in fact find evidence of ebullition, with 164 of the 1181 chamber observations (13.9\%) showing signs of ebullition (e.g. abrupt, non-linear changes in headspace concentrations). Of these 164 observations, 83 (7.0\%) showed net $\mathrm{CH} 4$ efflux (or, net ebullition), while a further 81 (6.9\%) showed very high rates of net $\mathrm{CH} 4$ uptake. The latter we termed "ebullition-driven $\mathrm{CH} 4$ uptake," due to the fact

Printer-friendly version

Discussion paper
Interactive comment 
that very high rates of $\mathrm{CH} 4$ uptake were observed following a putative bubble event. For these data, ebullition fluxes were calculated in one of two ways: for chambers showing steep non-linear increases, we fitted the data to a quadratic regression equation $(P<$ 0.05), and fluxes were determined from the steep initial rise in $\mathrm{CH} 4$ concentrations. For chambers showing abrupt stochastic increases, fluxes were determined by calculating the total $\mathrm{CH} 4$ production over the course of the bubble event, in-line with the approach used by the investigators in other studies (Teh et al., 2011). We decided to omit these data from the final dataset because we could not exclude the possibility that these fluxes were caused by sampling effects, despite the care we took (e.g. physical disturbance due to chamber placement or investigator movement; pressure effects caused by syringe sampling) led to ebullition. A summary of these ebullition data are presented in Supplementary Table 1 (below). We will revise the text to include a description of our data filtering procedure, and will also include the data shown in Supplementary Table 1 , to provide more information to the reader on ebullition.

With respect to chamber placement; this was achieved by using a 2-m long pole to lower the flux chambers onto the water or saturated soil. Gas samples were collected with syringes using $>2 \mathrm{~m}$ lengths of Tygon ${ }^{\circledR}$ tubing, after thoroughly purging the dead volumes in the sample lines. The text will be revised to provide these additional details on chamber placement and sampling technique.

5. Ebullition is relatively easy to detect e.g. if you start with very high concentrations or if you detect abrupt increases in $\mathrm{CH} 4$ concentration. Can you give us information on how you dealt which such data and how many of your chamber measurements were potentially affected by ebullition? Is there a correlation of flux strength and the potential occurrence of ebullition? You also mention in your discussion that you measured occasionally high $\mathrm{CH} 4$ uptake values (I. 477). Is it possible that this was related to high $\mathrm{CH} 4$ concentrations at the beginning of chamber closure, potentially caused by ebullition? Did you find a correlation between initial $\mathrm{CH} 4$ concentration and calculated $\mathrm{CH} 4$ uptake values? I was also wondering whether the contrasting seasonal emission

Printer-friendly version

Discussion paper
Interactive comment a 
patterns that you discuss (I. 417 and further) could be related to ebullition. As you see, I think you don't give use sufficient information about the potential occurrence of ebullition and you should clearly improve this.

Authors' response: Please see point 4 above. We did in fact see evidence of greater ebullition in higher emission environments. For example, ebullition was more common in Mixed Palm Swamp and M. flexuosa palm swamp (12.2 and $16.7 \%$ of observations for those vegetation types, respectively), which are the two vegetation types that showed the highest $\mathrm{CH} 4$ fluxes. In contrast, forested (short pole) and forested vegetation, which showed the lowest $\mathrm{CH} 4$ fluxes, saw the lowest occurrence of ebullition (i.e. 6.9 and $10.5 \%$ of observations, respectively). We also observed greater ebullition fluxes in the wet season, though the trend for ebullition-driven uptake was less clear. Due to the high variance in both ebullition and ebullition-driven uptake fluxes, we did not observe statistically significant differences in either of these rates among vegetation types, or between seasons. The text will be revised to include these data.

Regarding chambers that showed high oxidation rates; these high fluxes were in fact related to high initial concentrations, and we cannot exclude the possibility that these chambers could have been affected by ebullition, even if we did not see empirical evidence for this over the course of our chamber measurements (e.g. ebullition could have occurred immediately after chamber placement and before the first sample was taken). We will revise the discussion to recognise this possibility.

6. I have no problem with the fact that you measured negative $\mathrm{N} 2 \mathrm{O}$ fluxes, since we see more and more evidence that globally this is quite an important process. However, some of the negative fluxes seem to be quite high in your figure 2. How do your N2O uptake rates compare to other published values and is it possible that this may also somehow related to ebullition? Also, here I would be interested if your negative values correlate with the initially measured concentration in your chambers. If ebullition played a role for negative $\mathrm{Ch} 4$ and $\mathrm{N} 2 \mathrm{O}$ fluxes, you may expect that both strong $\mathrm{CH} 4$ uptake and $\mathrm{N} 2 \mathrm{O}$ uptake would occur in the same chamber measurement. Did you check this?

Printer-friendly version

Discussion paper 
Authors' response: Relative to other environments we have studied elsewhere in Peru (e.g. Kosñipata Valley, Manu National Park) and in the literature from upland environments, these uptake fluxes are very low; at least one order of magnitude lower than uptake fluxes observed in upland ecosystems (Teh et al., 2014). We believe it is highly unlikely that ebullition caused these trends, because we saw very little evidence of ebullition-driven $\mathrm{N} 2 \mathrm{O}$ fluxes (only 3 out of 1181 observations, or $0.3 \%$ ), and these data were filtered to remove these three observations from the analysis presented here. We also saw no evidence that strong $\mathrm{CH} 4$ uptake was correlated with $\mathrm{N} 2 \mathrm{O}$ uptake.

7. You probably measured your fluxes at different time of the day. Did you find any diurnal pattern in GHG fluxes? If yes, what could explain these observed differences and how would this affect your estimate of emission strength?

Authors' response: We did in fact conduct a study to investigate if gas fluxes showed evidence of diurnal variability, but did not find strong evidence of diurnal trends in fluxes. We will discuss this in the revised version of the manuscript.

8. The potential role of $\mathrm{CH} 4$ oxidation is remarkable absent from your discussion. Why is that the case? Do you think this is not important for the total measured $\mathrm{CH} 4$ fluxes?

Authors' response: For sake of brevity, we did not go discuss the potential role of gross $\mathrm{CH} 4$ oxidation in modulating net $\mathrm{CH} 4$ efflux. This is not because we did not believe gross $\mathrm{CH} 4$ oxidation was unimportant; rather, it was because we did not have the tools or the experimental design to make clear inferences about what proportion of produced $\mathrm{CH} 4$ was consumed prior to atmospheric egress. We do in fact believe that gross $\mathrm{CH} 4$ oxidation is very important, as demonstrated by past work in tropical systems that have used isotope tracers to deconvolve gross $\mathrm{CH} 4$ production and oxidation fluxes (von Fischer and Hedin, 2002;von Fischer and Hedin, 2007; Teh et al., 2005). For example, work by the lead author has demonstrated that gross methanotrophy may consume upwards of $48 \%$ of produced $\mathrm{CH} 4$ in tropical soils (Teh et al., 2005). Followup experiments at these study sites could explore this question in the future. We will

Printer-friendly version

Discussion paper 
revise the manuscript to include this information.

9 The version of the map in Fig. 1 that I saw did not have a very good quality. Can you provide a map where the four vegetation types that you used for stratification are included? The impression of Fig. 1 is that the total peat area is larger than what can be seen in the map. Can you adjust Fig. 1 in such a way that we see all of (or most of) the PMFB peatland area?

Authors' response: In the revised manuscript, we will provide a higher quality image than the one shown here, and will endeavour to include the information that the referee has requested.

REFERENCES Lahteenoja, O., Ruokolainen, K., Schulman, L., and Alvarez, J.: Amazonian floodplains harbour minerotrophic and ombrotrophic peatlands, Catena, 79, 140-145, 10.1016/j.catena.2009.06.006, 2009. Pangala, S. R., Moore, S., Hornibrook, E. R. C., and Gauci, V.: Trees are major conduits for methane egress from tropical forested wetlands, New Phytologist, 197, 524-531, 10.1111/nph.12031, 2013. Strack, M., Kellner, E., and Waddington, J. M.: Dynamics of biogenic gas bubbles in peat and their effects on peatland biogeochemistry, Global Biogeochemical Cycles, 19, n/a-n/a, 10.1029/2004GB002330, 2005. Teh, Y. A., Silver, W. L., and Conrad, M. E.: Oxygen effects on methane production and oxidation in humid tropical forest soils, Global Change Biology, 11, 1283-1297, 10.1111/j.1365-2486.2005.00983.x, 2005. Teh, Y. A., Silver, W. L., Sonnentag, O., Detto, M., Kelly, M., and Baldocchi, D. D.: Large Greenhouse Gas Emissions from a Temperate Peatland Pasture, Ecosystems, 14, 311-325, 10.1007/s10021-011-9411-4, 2011. Teh, Y. A., Diem, T., Jones, S., Huaraca Quispe, L. P., Baggs, E., Morley, N., Richards, M., Smith, P., and Meir, P.: Methane and nitrous oxide fluxes across an elevation gradient in the tropical Peruvian Andes, Biogeosciences, 11, 2325-2339, 10.5194/bg-11-2325-2014, 2014. von Fischer, J., and Hedin, L.: Separating methane production and consumption with a field-based isotope dilution technique., Global Biogeochemical Cycles, 16, 1-13, 10.1029/2001GB001448, 2002. von Fischer, J. C., and Hedin, L. O.: Controls on soil methane fluxes: Tests of

Printer-friendly version

Discussion paper

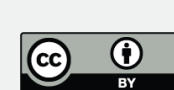


biophysical mechanisms using stable isotope tracers, Global Biogeochemical Cycles, 21, 9, Gb2007 10.1029/2006gb002687, 2007.

Please also note the supplement to this comment:

http://www.biogeosciences-discuss.net/bg-2017-48/bg-2017-48-AC1-supplement.pdf

Interactive comment on Biogeosciences Discuss., doi:10.5194/bg-2017-48, 2017. 
Supplementary Table 1. Table displaying the proportion of observation in each vegetation type that showed evidence of ebullition, mean rates of ebullition and ebullition-driven $\mathrm{CH}_{4}$ uptake. Values represent means and standard errors.

\begin{tabular}{|l|l|l|l|l|l|}
\hline Vegetation Type & $\begin{array}{l}\text { Percentage of } \\
\text { observations }\end{array}$ & $\begin{array}{l}\text { Ebullition } \\
\left(\mathrm{mg} \mathrm{CH}_{4}-\mathrm{C} \mathrm{m}^{-2} \mathrm{~d}^{-1}\right)\end{array}$ & \multicolumn{2}{l}{$\begin{array}{l}\text { Ebullition-driven uptake } \\
\left(\mathrm{mg} \mathrm{CH} \mathrm{C} \mathrm{m}^{-2} \mathrm{C}^{-1}\right)\end{array}$} \\
\hline & $(\%)$ & Wet Season & Dry Season & Wet Season & Dry Season \\
\hline Forested & 10.5 & N/A & N/A & N/A & $-136.4 \pm 0.1$ \\
\hline $\begin{array}{l}\text { Forested } \\
\text { (short pole) }\end{array}$ & 6.9 & $994.6 \pm 293.2$ & $512.5 \pm 153.0$ & $-95.8 \pm 0.0$ & $-245.5 \pm 48.9$ \\
\hline $\begin{array}{l}\text { M. flexuosa } \text { Palm } \\
\text { Swamp }\end{array}$ & 16.7 & $1192.0 \pm 305.7$ & $994.3 \pm 237.3$ & $-869.4 \pm 264.8$ & $-401.4 \pm 59.9$ \\
\hline $\begin{array}{l}\text { Mixed Palm } \\
\text { Swamp }\end{array}$ & 12.2 & N/A & $733.6 \pm 313.1$ & N/A & $-464.4 \pm 565.9$ \\
\hline
\end{tabular}

Fig. 1. 